\title{
Stage IIIB Uveal Melanoma AJCC v7
}

National Cancer Institute

\section{Source}

National Cancer Institute. Stage IIIB Uveal Melanoma A/CC V7. NCI Thesaurus. Code C88138.

Stage IIIB includes: (T3d, NO, M0); (T 4b-c, NO, M0). T3d: Ciliary body and choroid: Tumor size category 3 with ciliary body involvement and extraocular extension less than or equal to $5 \mathrm{~mm}$ in diameter. T4b: Iris: T umor with extrascleral extension more than $5 \mathrm{~mm}$ in diameter. Ciliary body and choroid: T umor size category 4 with ciliary body involvement. T4c: Ciliary body and choroid: T umor size category 4 without ciliary body involvement but with extraocular extension less than or equal to $5 \mathrm{~mm}$ in diameter. NO: No regional lymph node metastasis. M0: No distant metastasis. (AJCC 7th ed.) 